\title{
Site-specific health risk assessment of dioxins and furans in an industrial region with numerous emission sources
}

\author{
Wei-Yu Kao ${ }^{\mathrm{a}}$, Hwong-wen Ma ${ }^{\mathrm{a}, *}$, Lin-Chi Wang ${ }^{\mathrm{b}}$, Guo-Ping Chang-Chien ${ }^{\mathrm{b}}$ \\ ${ }^{a}$ Graduate Institute of Environmental Engineering, National Taiwan University, 71 Chou-Shan Road, Taipei 106, Taiwan \\ ${ }^{\mathrm{b}}$ Department of Chemical and Materials Engineering, Cheng Shiu University, 840, Chengching Rd., Kaohsiung 833, Taiwan
}

Received 10 July 2006; received in revised form 20 November 2006; accepted 20 November 2006

Available online 30 November 2006

\begin{abstract}
While the sources of releasing dioxins have received much attention, the health risks of incinerators are studied considerably more than those of other sources, such as metallurgical industry. Furthermore, risk assessments focus primarily on the effects of single sources; few have addressed the aggregate risks from multiple sources in a region. When many sources of dioxins exist in an area, such as the Industrial Park located in the densely populated district—Siaogang District in southern Taiwan where 17 primary known PCDD/F stationary emission sources are clustered, is the aggregate exposure to these sources imposing high risks even though individual sources comply with emission standards? The study combined the multimedia and multiple pathway exposure modeling and site-specific exposure scenario to assess dioxin risks contributed by the 17 emission sources in the District, including municipal waste incinerators, medical waste incinerators, sinter plants, electric arc furnace, secondary aluminum smelters, cement kilns, etc. The average cancer risk of a resident living in the District was found to be $3.43 \mathrm{E}-04$ under the site-specific exposure scenario. The top emission source is the sinter plant, followed by the electric arc furnace. The information has driven the local government to conduct more complete assessment and at the same time to consider enforcing a stricter local standard of dioxin emissions in the Siaogang District. (C) 2006 Elsevier B.V. All rights reserved.
\end{abstract}

Keywords: Sinter plant; Incinerators; Electric furnace; Metallurgical industry; PCDD/F; Risk assessment

\section{Introduction}

Polychlorinated dibenzo- $p$-dioxins (PCDD) and polychlorinated dibenzo furans (PCDF), commonly known as dioxins, are lipophilic organic compounds and ubiquitous environmental pollutants. Dioxin and its congeners are persistent organic pollutants (POPs) due to their ability to resist degradation and accumulate in terrestrial and aquatic ecosystems through the food chain. Because of their acute and chronic effects on the immune, nervous, endocrine, and reproductive systems and their carcinogenic potential, $\mathrm{PCDD} / \mathrm{Fs}$ have raised tremendous concerns.

PCDD/Fs are unintentionally formed and released from anthropogenic activities, especially from combustion processes and other thermal processes involving organic matter and chlorine. In the 1980s, sampling and analysis methods of PCDD/Fs started to be developed. A large number of studies have been

\footnotetext{
* Corresponding author. Tel.: +886 223630406; fax: +886223928830.

E-mail address: hwma@ntu.edu.tw (H.-w. Ma).
}

published since then, most of them focusing on emissions from municipal solid waste incinerators. Based on investigation of the emission inventory, it was recognized that waste incinerators were the predominant sources of dioxin release, accounting for in many industrial countries. For example, in the United Kingdom and the United States, emissions from municipal solid waste incinerators are the most significant sources of $\mathrm{PCDD} / \mathrm{Fs}$ to the atmosphere, contributing 30-56 and 38\%, more than other kinds of emission sources [1,2]. In Japan, emissions from municipal solid waste incinerators and industrial waste incinerators are the main PCDD/Fs sources, accounting for $87 \%$ of total quantified emissions [3].

In addition to incinerators, emissions from other thermal processes in the metallurgical industry are also important sources of dioxins; but there are fewer relevant studies on emission sources other than incinerators. In fact, emissions from waste combustion plants are lower than in the past because of installation of advanced pollution control systems and enactment of stricter regulations. Much attention is now directed towards other industrial emissions sources, including electric arc furnaces, secondary aluminum smelters, and sinter plants. The 
European Commission has suggested that electric arc furnaces, with increasing emissions to the air, are more important sources than incinerators in Europe [4]. Umweltbundesamt [5] found that dioxin emissions from a variety of electric arc furnaces in Germany ranged from $<0.1$ to $1.3 \mathrm{ng}$ International-Toxicity Equivalents (I-TEQ)/ $\mathrm{N} \mathrm{m}^{3}$. Fledler [6] investigated PCDD/Fs emissions from the stack gases of thirty secondary aluminum smelters, which yielded concentrations ranging from 0.02 to $21.5 \mathrm{ng}$ I-TEQ/ $\mathrm{N} \mathrm{m}^{3}$. In a study of the Lombardy Region (a highly industrialized area in Italy), municipal waste incinerators and steel production were the major PCDD/Fs sources. However, it was found that there was no reduction in the levels of PCDD/Fs emissions from other sources except for an 80-98\% reduction of incinerators in these years [7]. Schuhmacher et al. [8] investigated the pollutants emitted by a cement plant in Spain and found that air concentrations emitted by cement kilns ranged from $2.60 \mathrm{E}-09$ to $9.27 \mathrm{E}-09\left(\mathrm{ng} / \mathrm{m}^{3}\right)$.

The trend is more apparent in Taiwan. Wang et al. [9] found that the contribution from sinter plants (45 $\mathrm{g}$ I-TEQ/year) is $44-40 \%$ of total PCDD/F emissions in Taiwan. Chen [10] investigated the PCDD/Fs emissions inventory of Taiwan and found that the contribution of secondary copper smelters is more than $39 \%$ of the total dioxin emissions and is greater than those from all incinerators combined. Lee et al. [11] also found that the total PCDD/Fs emissions from electric arc furnaces $(20 \mathrm{~g} \mathrm{I}$ $\mathrm{TEQ} /$ year) and secondary aluminum smelters are 27, 53, and 24, 49 times higher than those from municipal solid waste incinerators $(0.74 \mathrm{~g}$ I-TEQ/year) and medical waste incinerators $(0.37 \mathrm{~g}$ I-TEQ/year), respectively.

Quantitative risk assessment is a useful tool to provide health impact estimation associated with various emission sources because it can link dioxin release to health risks in a systematic way. In past years, the carcinogenic and non-carcinogenic health risks associated with incinerators have been assessed. Ma et al. [12] assessed the carcinogenic risks of incinerator-emitted dioxins and risk transfer among the nine major municipal incinerators in Taiwan using site-specific risk assessment methods. Meneses et al. [13] calculated the incremental lifetime risk of dioxins for the population living in areas surrounding municipal waste incinerators. In addition, there have been many investigations addressing the human carcinogenic risk of dioxins through dietary exposure [14-16]. However, in spite of increased understanding of the emissions of industrial processes, there is still lack of discussion about health risks from metallurgical industry sources. Furthermore, the past and present risk assessments focus primarily on the effects of single sources or exposure routes; few have addressed the risk from multiple sources in a region and the interactive effects among different type of sources.

The Kaohsiung Lin-hai Industrial Park is located in the Siaogang District of Kaohsiung city, a highly industrialized city in southern Taiwan. The total area of the Siaogang District, which has about 150,000 inhabitants, is $398,573 \mathrm{~km}^{2}$ (comprising about $25.9 \%$ of Kaohsiung city). Established in the 1980s, the Kaohsiung Lin-hai Industrial Park is the center of metal production in Taiwan. The Taiwan Environmental Protection Agency has found that the primary known PCDD/F stationary emission sources of Kaohsiung city are mostly clustered in the Siaogang District, including municipal solid waste incinerators, medical waste incinerators, sinter plants, electric arc furnaces, secondary aluminum smelters, etc. Although industry is the main activity in the region due to this large industrial district, there is some cultivated land for the production of agricultural crops right close to the Kaohsiung Lin-hai Industrial Park. In this study, the characteristics of PCDD/Fs emissions from various stationary emission sources were determined by directly collecting and analyzing samples from the local stack flue gases. An effort was also made to assess the site-specific health risk from local dioxin emissions in the region. The main goals of this study were the following:

- To assess the human PCDD/Fs exposure due to all types of emission sources and evaluate the total heath risks for residents in the Siaogang District.

- To understand the contribution and distribution of the human health risk of PCDD/Fs from individual emission sources and to identify dominant dioxin sources in the region.

\section{Materials and methods}

To characterize the PCDD/Fs emissions from Kaohsiung city, it is necessary to identify potential emission sources in the area. Using the Geographic Information System (GIS) of the Taiwan Environmental Protection Agency, we searched the fixed pollution sources of highly industrialized cities in the list and found that most of the PCDD/Fs emission sources are in the Siaogang District. Seventeen predominant stationary emission sources with large exit flows and emission rates in Kaohsiung were selected for further sampling and analysis. The PCDD/Fs emission sources in the region could be classified into six types: incinerator, electric arc furnace, sinter plant, secondary aluminum smelter, coke-refining plant, and cement kiln, together contributing more than $90 \%$ of the total PCDD/Fs emissions of the city. Except for three emission sources, the sources are all located in the Siaogang District. The locations of these emission sources are shown in Fig. 1.

\subsection{Sampling and analysis}

For these stationary PCDD/Fs emissions sources, stack flue gas samples were collected according to USEPA Modified Method 23. In addition, air, soil, and vegetation samples were also collected. The sampling train adopted in this study is comparable with that specified by USEPA Modified Method 5. Prior to sampling, XAD-2 resin was spiked with PCDD/Fs surrogate standards pre-labeled with isotopes.

Analysis of stack flue gas and air samples followed USEPA Modified Method 23, and the analysis of soil and vegetation samples followed the USEPA Modified Method 1613. All chemical analyses were carried out by an internationally accredited laboratory with PCDD/Fs analyses of the Super Micro Mass Research and Technology Center in Cheng Shiu University in Taiwan. The sample analyses were performed according to standard procedures. High-resolution gas chromatographs/high- 


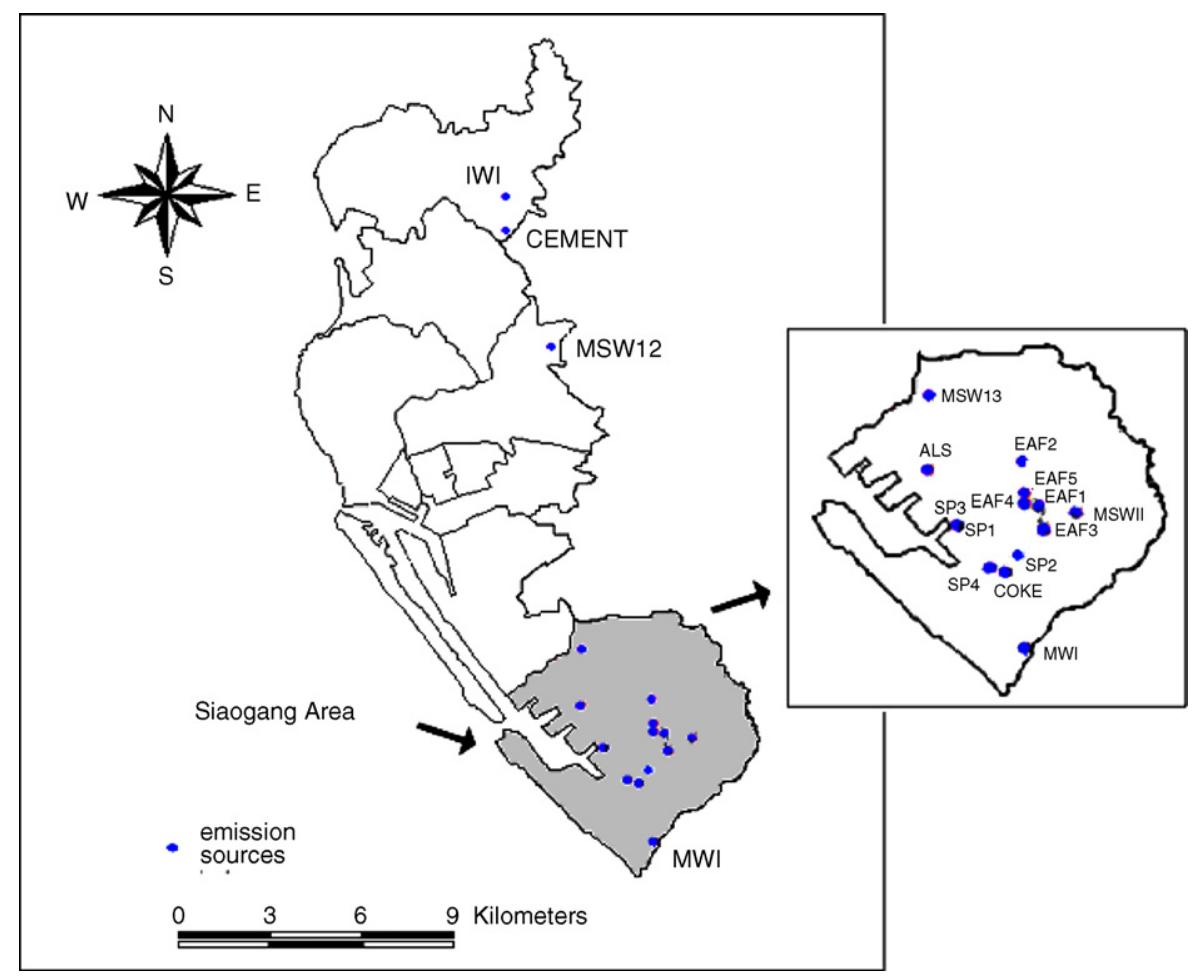

Fig. 1. The locations of the clustered PCDD/Fs emission sources in Kaohsiung city.

resolution mass spectrometers (HRGC/HRMS) were used for analyzing stack flue gas samples. The HRGC (Hewlett-Packard 6970 Series gas, CA) was equipped with a DB-5 MS fused silica capillary column (i.d. $=0.25 \mathrm{~mm}, L=60 \mathrm{~m}$, film thickness $=0.25 \mu \mathrm{m}$; J\&W Scientific, CA) and a splitless injection. The carrier gas was helium. The HRMS (Micromass Autospec Ultima, Manchester, UK) was equipped with a positive electron impact (EI+) source, and the analyzer mode of the selected ion monitoring (SIM) was used at a resolution of 10,000 . The electron energy and source temperature were specified at $35 \mathrm{eV}$ and $250^{\circ} \mathrm{C}$, respectively.

\subsection{Characterization of emission sources}

The 17 sources chosen for assessment were: five incinerators (including two municipal solid waste incinerators (MSWI), two industrial waste incinerators (IWI), and one medical waste incinerator (MWI)); five electric arc furnaces (EAF); four sinter plants (SP); a coke-refining plant (CFP); one secondary aluminum smelter (ALS); and a cement kiln (CK). Based on the results of stack gas sampling and analysis, the PCDD/Fs emission sources of Kaohsiung city could be characterized.

The average emission rates of the 17 dioxin congeners as well as the operation parameters and the characteristics are shown in Table 1. The exit flow of each emission source was already calibrated by the oxygen content of the individual stack gas. The emission rates of the dioxin congener profiles were average values of analytical results obtained from three to five stack gas samples of each stationary emission source during the year 2004.

\subsection{Multimedia and multiple-pathway exposure assessment modeling}

Multimedia and multiple pathway exposure modeling was used to estimate the exposure of the residents in the study area associated with all the identified sources emitting dioxins. The air deposition fluxes and ambient concentration of dioxins within the study area were estimated by use of a Gaussian plume air dispersion model, ISCST3 (Industrial Source Complex-Short Term, Version 3). This model estimated the concentrations of not only the various dioxin congeners in the particle phase, but also those in the gas phase. Results of the air dispersion model rely on three basic data sets: (1) meteorological conditions (wind speed and flow vector, ambient air temperature, stability class, and rural and urban mixing heights); (2) emission source characteristics (Table 1); and (3) cartographic data (length, latitude, and height). The dispersion of 17 dioxin congeners in the vapor and particle phase was modeled separately, and vapor-particle partition was incorporated to obtain average air concentrations and depositions. The dry deposition velocity was $0.2 \mathrm{~cm} / \mathrm{s}$ and the washout rates for various congeners ranged from 0.09 to 0.64 (with an average of 0.55 ). The potential impacted range of $\mathrm{PCDD} /$ Fs emissions was defined as the area of $10 \mathrm{~km} \times 10 \mathrm{~km}$ around each emission sources, and was divided into1600 sectors by a Cartesian grid. Air concentrations and depositions in each sector were modeled followed by estimation of concentrations in the other environmental media.

The subsequent multimedia exposure assessment was performed through a USEPA framework [17]. There are two connected parts in the multimedia exposure assessment process; 
Table 1

The operational parameters and the emission characteristics of the 17 emission sources clustered within Kaohsiung city

\begin{tabular}{|c|c|c|c|c|c|c|c|c|c|c|c|c|c|c|c|c|c|}
\hline \multirow{2}{*}{$\begin{array}{l}\text { Type of sources } \\
\text { Sources }\end{array}$} & \multicolumn{5}{|l|}{ Incinerators } & \multicolumn{5}{|c|}{ Electric arc furnaces } & \multicolumn{4}{|c|}{ Sinter Plants } & \multirow{2}{*}{$\begin{array}{l}\text { Coke- } \\
\text { refining } \\
\text { plants }\end{array}$} & \multirow{2}{*}{$\begin{array}{l}\text { Secondary } \\
\text { aluminum } \\
\text { smelter }\end{array}$} & \multirow{2}{*}{$\begin{array}{l}\text { Cement } \\
\text { kiln }\end{array}$} \\
\hline & MSWI1 & MSWI2 & IWI1 & IWI2 & MWI & EAF1 & EAF2 & EAF3 & EAF4 & EAF5 & SP1 & SP2 & SP3 & SP4 & & & \\
\hline Exit flow (dscm/min) & 1701.41 & 1050 & 123.9 & 235.10 & 119.67 & 4886.5 & 6701.77 & 9355.61 & 11939.5 & 9600 & 16834.13 & 8839.24 & 11254.68 & 12485.67 & 27463.1 & 1450.68 & 4792.07 \\
\hline Exit temerature $\left({ }^{\circ} \mathrm{C}\right)$ & 150.0 & 140.0 & 170.0 & 280.00 & 160 & 110 & 110 & 200 & 100 & 70 & 100 & 150 & 110 & 140 & 130 & 100 & 140 \\
\hline Stack height $(\mathrm{m})$ & 90.0 & 104 & 22.3 & 50.0 & 24.0 & 29.0 & 25.0 & 23.3 & 21.8 & 30.0 & 55.0 & 73.0 & 98.0 & 73.0 & 125 & 14.0 & 50.2 .5 \\
\hline \multicolumn{18}{|l|}{ Emission rate $(\mathrm{g} / \mathrm{s})$} \\
\hline 2,3,7,8-TeCDD & $1.49 \mathrm{E}-10$ & $1.44 \mathrm{E}-11$ & $2.69 \mathrm{E}-10$ & $2.50 \mathrm{E}-11$ & $1.73 \mathrm{E}-10$ & $7.40 \mathrm{E}-10$ & $1.45 \mathrm{E}-09$ & $1.71 \mathrm{E}-09$ & $1.72 \mathrm{E}-09$ & $3.2 \mathrm{E}-09$ & $7.98 \mathrm{E}-09$ & $4.07 \mathrm{E}-09$ & $7.65 \mathrm{E}-09$ & $4.32 \mathrm{E}-09$ & $3.20 \mathrm{E}-10$ & $3.70 \mathrm{E}-09$ & $1.46 \mathrm{E}-09$ \\
\hline $1,2,3,7,8-\mathrm{PeCDD}$ & $6.57 \mathrm{E}-10$ & $7.72 \mathrm{E}-11$ & $1.94 \mathrm{E}-09$ & $8.79 \mathrm{E}-11$ & $1.69 \mathrm{E}-10$ & $1.32 \mathrm{E}-09$ & $3.05 \mathrm{E}-09$ & $3.9 \mathrm{E}-09$ & $3.15 \mathrm{E}-09$ & $7.39 \mathrm{E}-09$ & $2.25 \mathrm{E}-08$ & $9.30 \mathrm{E}-09$ & $3.05 \mathrm{E}-08$ & $8.29 \mathrm{E}-09$ & $9.36 \mathrm{E}-10$ & $5.66 \mathrm{E}-09$ & $7.86 \mathrm{E}-10$ \\
\hline $1,2,3,4,7,8-\mathrm{HxCDD}$ & $9.97 \mathrm{E}-10$ & $1.26 \mathrm{E}-10$ & $2.90 \mathrm{E}-09$ & $4.96 \mathrm{E}-11$ & $2.70 \mathrm{E}-11$ & $6.48 \mathrm{E}-10$ & $1.66 \mathrm{E}-09$ & $2.24 \mathrm{E}-09$ & $1.44 \mathrm{E}-09$ & $4.02 \mathrm{E}-09$ & $1.40 \mathrm{E}-08$ & $4.72 \mathrm{E}-09$ & $2.52 \mathrm{E}-08$ & $4.41 \mathrm{E}-09$ & $5.69 \mathrm{E}-10$ & $3.66 \mathrm{E}-09$ & $2.07 \mathrm{E}-10$ \\
\hline $1,2,3,6,7,8-\mathrm{HxCDD}$ & $2.03 \mathrm{E}-09$ & $3.48 \mathrm{E}-10$ & $5.89 \mathrm{E}-09$ & $8.75 \mathrm{E}-11$ & $3.18 \mathrm{E}-11$ & $9.88 \mathrm{E}-10$ & 4.07E-09 & $5.32 \mathrm{E}-09$ & $3.01 \mathrm{E}-09$ & $1.01 \mathrm{E}-08$ & $2.08 \mathrm{E}-08$ & 7.40E-09 & $5.63 \mathrm{E}-08$ & $7.33 \mathrm{E}-09$ & $7.33 \mathrm{E}-10$ & $6.32 \mathrm{E}-09$ & $3.09 \mathrm{E}-10$ \\
\hline $1,2,3,7,8,9-\mathrm{HxCDD}$ & $1.46 \mathrm{E}-09$ & $2.40 \mathrm{E}-10$ & $3.83 \mathrm{E}-09$ & $7.07 \mathrm{E}-11$ & $4.69 \mathrm{E}-11$ & $7.23 \mathrm{E}-10$ & $2.93 \mathrm{E}-09$ & 4.49E-09 & $1.97 \mathrm{E}-09$ & $5.96 \mathrm{E}-09$ & $1.67 \mathrm{E}-08$ & $5.75 \mathrm{E}-09$ & $3.16 \mathrm{E}-08$ & $5.11 \mathrm{E}-09$ & $7.58 \mathrm{E}-10$ & $3.85 \mathrm{E}-09$ & $2.61 \mathrm{E}-10$ \\
\hline $1.2 .3 .4 .6 .7 .8-\mathrm{HpCDD}$ & $1.55 \mathrm{E}-08$ & $2.97 \mathrm{E}-09$ & $3.36 \mathrm{E}-08$ & $4.58 \mathrm{E}-10$ & $5.87 \mathrm{E}-11$ & $3.25 \mathrm{E}-09$ & $1.49 \mathrm{E}-08$ & $1.12 \mathrm{E}-08$ & $7.73 \mathrm{E}-09$ & $4.55 \mathrm{E}-08$ & $8.04 \mathrm{E}-08$ & $3.08 \mathrm{E}-08$ & $2.55 \mathrm{E}-07$ & $2.52 \mathrm{E}-08$ & $2.64 \mathrm{E}-09$ & $1.51 \mathrm{E}-08$ & $1.09 \mathrm{E}-09$ \\
\hline OCDD & $2.11 \mathrm{E}-08$ & $4.42 \mathrm{E}-09$ & $2.88 \mathrm{E}-08$ & $8.34 \mathrm{E}-10$ & $4.19 \mathrm{E}-11$ & $4.95 \mathrm{E}-09$ & $1.73 \mathrm{E}-08$ & $1.02 \mathrm{E}-08$ & $1.04 \mathrm{E}-08$ & $4.68 \mathrm{E}-08$ & $9.59 \mathrm{E}-08$ & $4.41 \mathrm{E}-08$ & $3.23 \mathrm{E}-07$ & $4.43 \mathrm{E}-08$ & $5.60 \mathrm{E}-09$ & $1.30 \mathrm{E}-08$ & $1.79 \mathrm{E}-09$ \\
\hline 2,3,7,8-TeCDF & $9.84 \mathrm{E}-10$ & $8.49 \mathrm{E}-11$ & $3.01 \mathrm{E}-09$ & $2.49 \mathrm{E}-10$ & $1.40 \mathrm{E}-09$ & $7.65 \mathrm{E}-09$ & $2.79 \mathrm{E}-08$ & $5.91 \mathrm{E}-08$ & $2.11 \mathrm{E}-08$ & $5.01 \mathrm{E}-08$ & $3.15 \mathrm{E}-07$ & $1.24 \mathrm{E}-07$ & $3.58 \mathrm{E}-07$ & $1.24 \mathrm{E}-07$ & $3.71 \mathrm{E}-09$ & $6.34 \mathrm{E}-08$ & $9.14 \mathrm{E}-09$ \\
\hline $1,2,3,7,8-\mathrm{PeCDF}$ & $1.31 \mathrm{E}-09$ & $1.23 \mathrm{E}-10$ & $5.30 \mathrm{E}-09$ & $3.77 \mathrm{E}-10$ & $7.17 \mathrm{E}-10$ & $6.96 \mathrm{E}-09$ & $1.49 \mathrm{E}-08$ & $3.06 \mathrm{E}-08$ & $1.26 \mathrm{E}-08$ & $3.5 \mathrm{E}-08$ & $2.59 \mathrm{E}-07$ & $8.91 \mathrm{E}-08$ & $3.30 \mathrm{E}-07$ & $8.41 \mathrm{E}-08$ & $5.31 \mathrm{E}-09$ & $3.74 \mathrm{E}-08$ & $3.19 \mathrm{E}-09$ \\
\hline 2,3,4,7,8-PeCDF & $1.17 \mathrm{E}-09$ & $2.77 \mathrm{E}-10$ & $1.95 \mathrm{E}-08$ & $4.98 \mathrm{E}-10$ & $3.67 \mathrm{E}-10$ & $8.2 \mathrm{E}-09$ & $2.27 \mathrm{E}-08$ & $2.07 \mathrm{E}-08$ & $2.3 \mathrm{E}-08$ & $7.16 \mathrm{E}-08$ & $3.16 \mathrm{E}-07$ & $1.14 \mathrm{E}-07$ & $5.24 \mathrm{E}-07$ & $1.24 \mathrm{E}-07$ & $5.28 \mathrm{E}-09$ & $6.57 \mathrm{E}-08$ & $3.08 \mathrm{E}-09$ \\
\hline $1,2,3,4,7,8-\mathrm{HxCDF}$ & $1.84 \mathrm{E}-09$ & $1.33 \mathrm{E}-10$ & $1.35 \mathrm{E}-08$ & $4.55 \mathrm{E}-10$ & $2.83 \mathrm{E}-10$ & $6.69 \mathrm{E}-09$ & $1.09 \mathrm{E}-08$ & $2.15 \mathrm{E}-08$ & $7.52 \mathrm{E}-09$ & $2.01 \mathrm{E}-08$ & $2.56 \mathrm{E}-07$ & 7.44E-08 & $3.24 \mathrm{E}-07$ & $6.42 \mathrm{E}-08$ & $5.39 \mathrm{E}-09$ & $3.33 \mathrm{E}-08$ & $1.06 \mathrm{E}-09$ \\
\hline $1,2,3,6,7,8-\mathrm{HxCDF}$ & $2.28 \mathrm{E}-09$ & $3.02 \mathrm{E}-10$ & $1.78 \mathrm{E}-08$ & $4.76 \mathrm{E}-10$ & $2.78 \mathrm{E}-10$ & $6.66 \mathrm{E}-09$ & $1.1 \mathrm{E}-08$ & $2.28 \mathrm{E}-08$ & $9.8 \mathrm{E}-09$ & $2.25 \mathrm{E}-08$ & $2.45 \mathrm{E}-07$ & $6.91 \mathrm{E}-08$ & $3.10 \mathrm{E}-07$ & $5.84 \mathrm{E}-08$ & $5.88 \mathrm{E}-09$ & $3.15 \mathrm{E}-08$ & $1.41 \mathrm{E}-09$ \\
\hline $1,2,3,7,8,9-\mathrm{HxCDF}$ & $2.18 \mathrm{E}-10$ & $1.61 \mathrm{E}-11$ & $1.90 \mathrm{E}-09$ & $3.58 \mathrm{E}-11$ & $1.20 \mathrm{E}-11$ & $3.43 \mathrm{E}-10$ & $6.78 \mathrm{E}-10$ & $1.45 \mathrm{E}-09$ & $6.74 \mathrm{E}-10$ & $1.79 \mathrm{E}-09$ & $1.94 \mathrm{E}-08$ & $5.03 \mathrm{E}-09$ & $1.59 \mathrm{E}-08$ & $3.20 \mathrm{E}-09$ & $4.01 \mathrm{E}-10$ & $1.55 \mathrm{E}-09$ & $5.19 \mathrm{E}-11$ \\
\hline $2,3,4,6,7,8-\mathrm{HxCDF}$ & $2.48 \mathrm{E}-09$ & $4.36 \mathrm{E}-10$ & $4.88 \mathrm{E}-08$ & $4.19 \mathrm{E}-10$ & $1.50 \mathrm{E}-10$ & $5.04 \mathrm{E}-09$ & $1.16 \mathrm{E}-08$ & $1.63 \mathrm{E}-08$ & $1.16 \mathrm{E}-08$ & $3.57 \mathrm{E}-08$ & $2.25 \mathrm{E}-07$ & $6.46 \mathrm{E}-08$ & $2.77 \mathrm{E}-07$ & $5.03 \mathrm{E}-08$ & 4.47E-09 & $3.00 \mathrm{E}-08$ & $1.28 \mathrm{E}-09$ \\
\hline $1,2,3,4,6,7,8-\mathrm{HpCDF}$ & $4.78 \mathrm{E}-09$ & $7.29 \mathrm{E}-10$ & $6.64 \mathrm{E}-08$ & $9.09 \mathrm{E}-10$ & $2.52 \mathrm{E}-10$ & $9.48 \mathrm{E}-09$ & $2.02 \mathrm{E}-08$ & $2.81 \mathrm{E}-08$ & $1.29 \mathrm{E}-08$ & $4.62 \mathrm{E}-08$ & $3.89 \mathrm{E}-07$ & $9.75 \mathrm{E}-08$ & $5.32 \mathrm{E}-07$ & $8.16 \mathrm{E}-08$ & $1.04 \mathrm{E}-08$ & $4.90 \mathrm{E}-08$ & $1.78 \mathrm{E}-09$ \\
\hline $1,2,3,4,7,8,9-\mathrm{HpCDF}$ & $1.43 \mathrm{E}-09$ & $1.25 \mathrm{E}-10$ & $1.51 \mathrm{E}-08$ & $1.36 \mathrm{E}-10$ & $1.99 \mathrm{E}-11$ & $1.58 \mathrm{E}-09$ & $3.98 \mathrm{E}-09$ & $4.85 \mathrm{E}-09$ & $2.06 \mathrm{E}-09$ & $1.19 \mathrm{E}-08$ & $6.86 \mathrm{E}-08$ & $1.60 \mathrm{E}-08$ & $6.07 \mathrm{E}-08$ & $1.08 \mathrm{E}-08$ & $1.66 \mathrm{E}-09$ & $6.36 \mathrm{E}-09$ & $3.07 \mathrm{E}-10$ \\
\hline OCDF & $2.08 \mathrm{E}-09$ & $4.52 \mathrm{E}-10$ & $4.91 \mathrm{E}-08$ & $3.01 \mathrm{E}-10$ & $2.93 \mathrm{E}-11$ & $4.76 \mathrm{E}-09$ & $1.44 \mathrm{E}-08$ & $8.98 \mathrm{E}-09$ & $8.95 \mathrm{E}-09$ & $4.13 \mathrm{E}-08$ & $1.05 \mathrm{E}-07$ & $2.18 \mathrm{E}-08$ & $7.52 \mathrm{E}-08$ & $3.45 \mathrm{E}-08$ & $3.09 \mathrm{E}-09$ & $1.55 \mathrm{E}-08$ & $7.35 \mathrm{E}-10$ \\
\hline Total Er & $2.60 \mathrm{E}-09$ & $4.09 \mathrm{E}-10$ & $2.22 \mathrm{E}-08$ & $5.37 \mathrm{E}-10$ & $7.03 \mathrm{E}-10$ & $8.88 \mathrm{E}-09$ & $2.26 \mathrm{E}-08$ & $2.93 \mathrm{E}-08$ & $2.14 \mathrm{E}-08$ & $6.06 \mathrm{E}-08$ & $3.07 \mathrm{E}-07$ & $1.07 \mathrm{E}-07$ & $4.50 \mathrm{E}-07$ & $1.08 \mathrm{E}-07$ & $6.04 \mathrm{E}-09$ & $5.93 \mathrm{E}-08$ & $4.96 \mathrm{E}-09$ \\
\hline Concentration (ng-TEQ/ $\left.\mathrm{N} \mathrm{m}^{3}\right)$ & 0.092 & 0.023 & 10.245 & 0.137 & 0.861 & 0.109 & 0.202 & 0.188 & 0.108 & 0.378 & 1.095 & 0.726 & 2.400 & 0.518 & 0.066 & 2.454 & 0.062 \\
\hline
\end{tabular}


the first is multimedia transport and transformation modeling, and the second is multiple-pathway exposure modeling. As the first step, multimedia transport and transformation modeling was used to calculate the temporal and spatial distribution in various environmental media as a result of air concentration and deposition of dioxins. The multiple-pathway exposure model was then used to predict the exposure dose a typical resident would receive through various pathways of contact. Twelve exposure pathways were considered, including air inhalation, ingestion of contaminated soil, drinking water, and food (nine items). The results of the exposure-assessment step were the estimated averaged daily intakes (ADIs) of 17 dioxin congeners. The following equation was used to calculate the average daily intake of dioxins, $\mathrm{ADI}_{i j}$ (mg-TEQ/kg/day) meaning the exposure from an environmental medium $i$ (such as air and soil) and an exposure medium $j$ (such as milk and eggs):

$\mathrm{ADI}_{i j}=\sum_{k}\left(C_{i j k} \times \mathrm{TEF}_{k}\right) \times \frac{\mathrm{IU}_{j}}{\mathrm{BW}} \times \frac{\mathrm{EF} \times \mathrm{ED}}{\mathrm{AT}}$

where $C_{i j k}$ is the concentration of the dioxin congener $k$ in the exposure medium $j$ from environmental medium $i ; \mathrm{TEF}_{k}$ is the international toxicity equivalency factor (I-TEF set by 1988 NATO/CCMS) [18] of congener $k$ based on its relative toxicity and activity to $2,3,7,8-\mathrm{TCDD} ; \mathrm{IU}_{j}$ is the contact rate of exposure medium $j$; EF and ED are the exposure frequency and exposure duration, respectively; AT is the average lifetime; and BW is the body weights of risk receptors.

\subsection{Risk characterization}

The carcinogenic risk of PCDD/Fs was calculated by multiplying the estimated dose by the carcinogenic potency factor for dioxins. The carcinogenic potency factor used in the model was $156,000(\mathrm{mg} / \mathrm{kg} / \mathrm{day})^{-1}[19]$. The predicted carcinogenic risk is an estimated value of potential risk associated with the exposure scenarios. A risk from a single emission source was calculated by summing the carcinogenic risk of the PCDD/Fs to each exposure pathway [20] and the total risks in the region comprised the individual risks from 17 emission sources.

\subsection{The site-specific exposure scenario}

In the study, the results of sampling and measurement were combined with the air dispersion model and multimedia model to assess the cancer risk in the region. In order to simulate the exposure processes as close to the actual situations as possible, we set a site-specific exposure scenario, including site-specific environmental and exposure parameters, which matched the local lifestyle. In addition to the meteorological basic data in the ISCST3 model, the site-specific environmental parameters also included the parameters concerned with local topography, geographical feature, soil structure, and hydrology. The sitespecific exposure parameters included the multi-pathway intake factors and the site-specific transfer factors. The multi-pathway intake factor was mainly the intake rate of various routes (inhalation and ingestion). Except for the ingestion rate of soil, the multi-pathway intake factors were determined from the statistical results of the Nutrition and Health Survey in Taiwan [21], including inhalation rate, intake of drinking water, and ingestion rates of various food items. The Survey was a nutritional and health study conducted through questionnaires; it presented information about the daily dietary intake of Taiwan citizens according to age, sex, lifestyle, and region. Food groups were the following: meats (beef, pork, chicken, and fish), vegetables (root and aboveground), fruit, eggs, and dairy. In the case of the soil ingestion rate, we assumed the intake of soil to be only incidental with food ingestion and adopted the $50 \mathrm{mg} /$ day suggested by the USEPA.

The site-specific transfer factors represented the degree to which the dioxin risk would be transferred by wholesalemarketed food. The basis of the parameters was the statistics information gathered over several years and reported in Food Supply and Utilization Yearbook 2003 [22]. The Yearbook provided information about total annual yields, cultivated lands of agricultural production throughout the country, and local yields in the Siaogang District. The site-specific transfer factor was calculated as follows:

site-specific transfer factor

$$
=\frac{\text { local values (areas, yields) }}{\text { national total values (areas, yields) }}
$$

From the equation, we obtained the site-specific transfer factors of various food groups (Table 2). These values indicated the fraction of the nine food items produced from the Siaogang District. It was assumed that only the food produced in the District would be contaminated by the emission sources; the contamination of food from other areas was not taken into account. In other words, the site-specific transfer factors reflected the likelihood that residents ate food contaminated by local emission sources.

In past studies, the main exposure pathway of the dioxin risk was food ingestion, normally accounting for more than $90 \%$ of the total risk [23,24,12]; thus, the assumption of intake exposure is important. Although there are agricultural products grown in the District, the food supply and distribution system is complicated due to the supply-consumption network of various food items from all cities and counties.

Table 2

The agricultural production yields of the Whole Nation and the Siaogang District and the calculated site-specific transfer factors

\begin{tabular}{|c|c|c|c|c|c|c|}
\hline & Cultivated lands (ha) & Hog (amount) & Meat cattle (amount) & Poultry (amount) & Fish (tonne) $)^{\mathrm{a}}$ & Dairy cattle (amount) \\
\hline Taiwan & 847,334 & $6,793,941$ & 149,459 & $131,704,000$ & $1,405,092$ & 64,517 \\
\hline Siaogang District & 356.83 & 337 & 2 & 19,000 & 230,253 & 23 \\
\hline Site-specific transfer factors & $4.21 \mathrm{E}-04$ & $4.96 \mathrm{E}-05$ & $1.34 \mathrm{E}-05$ & $1.44 \mathrm{E}-04$ & $1.64 \mathrm{E}-01$ & $3.57 \mathrm{E}-04$ \\
\hline
\end{tabular}


Table 3

The daily intake rates of the site-specific exposure scenario

\begin{tabular}{|c|c|c|c|c|}
\hline Food groups & $\begin{array}{l}\text { Daily dietary } \\
\text { ingestion rate }^{\mathrm{a}}\end{array}$ & $\begin{array}{l}\text { Degree of food } \\
\text { self-sufficiency }\end{array}$ & $\begin{array}{l}\text { Site-specific } \\
\text { transfer factors }\end{array}$ & $\begin{array}{l}\text { Daily intake of the site-specific } \\
\text { exposure scenario }\end{array}$ \\
\hline Aboveground vegetables & 443.07 & 0.62 & $4.21 \mathrm{E}-04$ & $1.15 \mathrm{E}-01$ \\
\hline Root vegetables & 110.41 & 0.78 & $4.21 \mathrm{E}-04$ & $3.63 \mathrm{E}-02$ \\
\hline Beef & 5.49 & 0.07 & $1.34 \mathrm{E}-05$ & $5.29 \mathrm{E}-06$ \\
\hline Pork & 107.20 & 0.99 & $4.96 \mathrm{E}-05$ & $5.24 \mathrm{E}-03$ \\
\hline Chicken & 51.18 & 0.98 & $1.44 \mathrm{E}-04$ & $7.21 \mathrm{E}-03$ \\
\hline Fish & 24.17 & 1 & $1.64 \mathrm{E}-01$ & $3.96 \mathrm{E}+00$ \\
\hline Soil & 0.05 & & $4.21 \mathrm{E}-04$ & $2.11 \mathrm{E}-05$ \\
\hline
\end{tabular}

Unit: g DW/day.

a The adult intake rates of the food groups in Taiwan [21].

The site-specific exposure scenario considered the effect of food sale and distribution and was established on the following assumptions: (1) the residents' daily intake of food produced from the Siaogang District might be contaminated through environmental transport and transformation following the considered emissions, while the food from other areas contained no dioxins; (2) agricultural products in source-impacted areas were stable and could meet all residents' consumption needs; (3) the probability of getting contaminated food from the District was the same regardless of whether the subject was living in the study area. The probability of obtaining contaminated food was based on site-specific transfer factors.

The original ingestion rates are the adult intake rates of the food groups in Taiwan [21]. Using the site-specific transfer factors and degree of food self-sufficiency (i.e. the ratio of the domestic food supply over the total food demand) in Taiwan for the various food items, we can obtain the exposure scenario with site-specific dietary intake. The cultivated lands ratio of Taiwan and the Siaogang District was the transfer factor used to calculate the transfer percentage of vegetal food, including aboveground vegetables, root vegetables, and fruit. The intake rates of chicken and eggs were obtained based on the poultry parameter. The intake rates of pork, beef, dairy, and fish were obtained according to the site-specific transfer factors of hog, meat beef, dairy cattle, and fish, respectively. Table 3 presents the daily intake rates of food items for the site-specific exposure scenario.

\section{Results and discussion}

\subsection{The characteristics of emission sources and the concentrations in the environmental media}

From the analysis results shown in Table 1, the emission rates ranged from $4.09 \mathrm{E}-10$ to $4.50 \mathrm{E}-07 \mathrm{~g}^{\mathrm{TEQ}} \mathrm{s}^{-1}$. The source with the highest emission rates was the sinter plant SP3, and that with the lowest rates was the incinerator MSWI2. As a whole, the four sinter plants had the highest emission rates, ranging from $1.07 \mathrm{E}-07$ to $4.50 \mathrm{E}-07$. $\mathrm{PCDD} / \mathrm{Fs}$ concentrations of these stationary emission sources ranged from 0.02 to $10.25 \mathrm{ng}$ I-TEQ/ $/ \mathrm{N} \mathrm{m}^{3}$. Most of the sources had mean concentra- tions less than $2 \mathrm{ng}$-TEQ/ $/ \mathrm{N} \mathrm{m}^{3}$, except for five sources, including the incinerator IWI1, the two electric arc furnaces EAF2 and EAF5, the sinter plant SP3, and the secondary aluminum smelter. There is currently no consistent legislation governing emission concentrations of PCDD/Fs in Taiwan. The regulations for incinerators are different for different sizes of incinerators; the acceptable levels for large incinerators and medium/small incinerators are 0.1 and $0.5 \mathrm{ng}-\mathrm{TEQ} / \mathrm{N} \mathrm{m}^{3}$, respectively. The regulations for electric arc furnaces and sinter plants are $5 \mathrm{ng}$ $\mathrm{TEQ} / \mathrm{N} \mathrm{m}^{3}$ and $2 \mathrm{ng}$-TEQ/N $\mathrm{m}$ but were not in effect before 2004 and 2005, respectively. There are no regulations on the other emission sources. Only the emission concentrations of IWI1 and SP3 exceeded the regulatory standards.

Table 4 shows the sampling concentrations of air, soil, and vegetations in the District. The concentrations in these sampled environmental media in the study area were found to be higher when compared with other places of Taiwan; in particular the soil concentrations were shown about 10 times those in other places of Taiwan.

\subsection{The results of risk assessment}

Table 5 shows the estimated risks from 12 exposure pathways for the 17 dioxin emission sources in the Siaogang District under the site-specific exposure scenario. The total cancer risk to the residents was calculated as the sum of the individual risks for 17 emission sources. The total cancer risk of an adult living in the area was $3.43 \mathrm{E}-04$ under the site-specific exposure scenario. The individual risk of these emission sources ranged from 3.51E-14 (Municipal Solid Waste Incinerator 2) to 2.83E-04

Table 4

The PCDD/Fs concentrations of environmental media (air, soil, and vegetations) of site-specific sampling locations in the study about the Siaogang District

\begin{tabular}{|c|c|c|c|}
\hline Media & Average & Maximum & Minimum \\
\hline \multicolumn{4}{|c|}{ Total PCDD/Fs (pg I-TEQ/N m ${ }^{3}$ ) } \\
\hline Air & 0.12 (R.S.D. $=67.6, n=9$ ) & 0.26 & 0.0576 \\
\hline \multicolumn{4}{|c|}{ Total PCDD/Fs (pg I-TEQ/g) } \\
\hline Soil & 10.6 (R.S.D. $=93.7, n=8)$ & 32.3 & 1.05 \\
\hline Vegetation & 9.49 (R.S.D. $=38.0, n=9$ ) & 15.8 & 4.21 \\
\hline
\end{tabular}




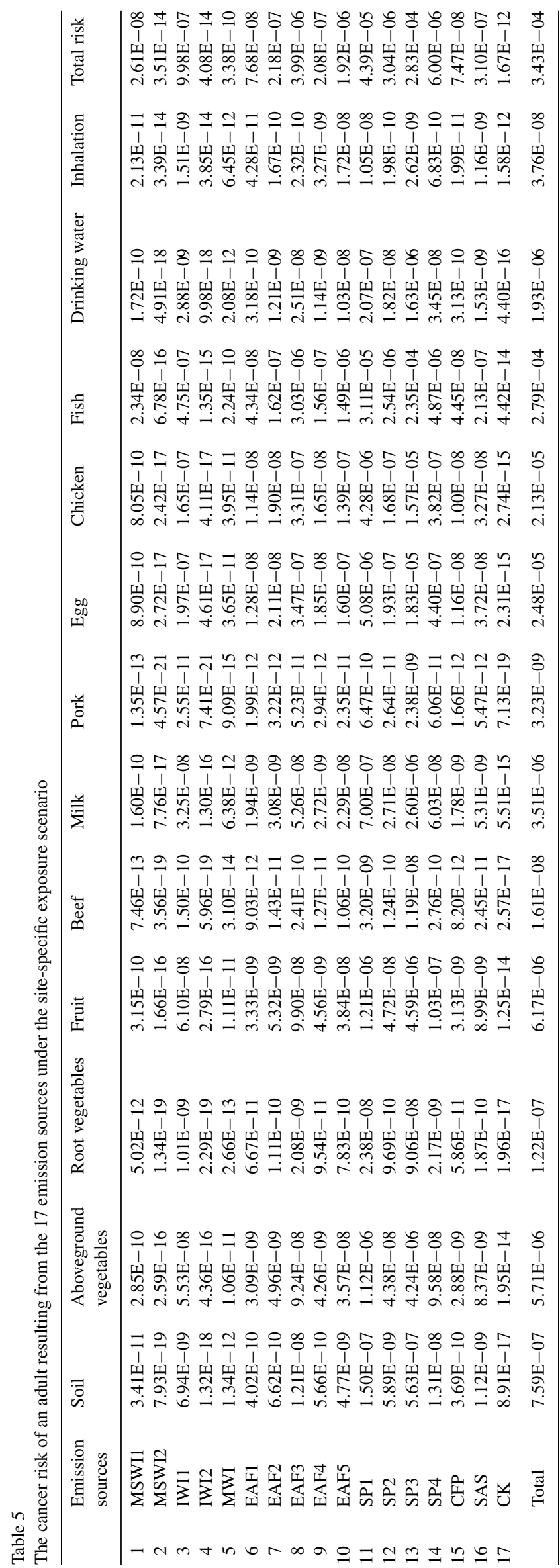

(Sinter Plant 3). Generally speaking, a safe level of carcinogenic risk usually ranges from $1 \mathrm{E}-04$ to $1 \mathrm{E}-06$, and a health risk less than $1 \mathrm{E}-06$ would be regarded as acceptable. Aside from four the sinter plants (SP1, SP2, SP3, and SP4) and the two electric arc furnaces (EAF3, EAF5) with higher exit flows and dioxin concentrations than the others, there were 11 emission sources with estimated risk less than 1E-06 in the Siaogang District among the 17 emission sources. Over these six high-risk emission sources, there were still two emission sources, Sinter plant 1 (SP1) and Sinter plant 3 (SP3) that contributed a cancer risk of more than $1 \mathrm{E}-05$ to the region.

In the results of the site-specific exposure scenario, the ingestion of nine food groups was the main route of dioxin exposure, accounting for 3.42E-04, or more than $99 \%$ of the total cancer risk. From both the results of risk assessments and the direct sampling of the environmental media, it was apparent that the people living in the Siaogang District with lots of stationary emission sources were subject to higher potential of dioxin risks.

\subsection{Comparisons of the cancer risks in the Siaogang District}

\subsubsection{Comparisons of the types of emission sources}

In comparison of the individual cancer risk of the 17 emission sources in the impacted area, the sinter plants SP3 and SP1 were the highest risk sources, contributing to the total risk by 82.31 and $12.78 \%$, respectively, or more than $90 \%$ combined. In contrast to these high risk sources, the PCDD/Fs risk due to other types of emission sources was much lower, including the secondary aluminum smelter, cement plant, coke-refining plant, and incinerator. Among the remainder, the risk contributions of PCDD/Fs emissions from the incinerators MSWI2, IWI1 and the cement kiln were the lowest, at less than $0.0001 \%$ of the total. This is because these three emission sources are away from the impacted area of the other emission sources.

Table 6 shows the cancer risk from the six types of emission sources in the District. It can be concluded that the primary cancer risk in the District was from the sinter plants. In the site-specific exposure scenario, the sum of the cancer risk contributions from the four sinter plants is greater than $97 \%$, with a total risk of $3.36 \mathrm{E}-04$. The next-highest source of emissions was the electric arc furnace; the risk contributions of the five electric arc furnaces accounted for nearly $2 \%$. Despite the fact

Table 6

The cancer risk from different types of emission sources under site-specific exposure scenario

\begin{tabular}{lllll}
\hline $\begin{array}{l}\text { Type of emission } \\
\text { sources }\end{array}$ & $\begin{array}{l}\text { Drinking } \\
\text { water }\end{array}$ & Inhalation & Ingestion & Total risk \\
\hline Incinerator & $3.05 \mathrm{E}-09$ & $1.54 \mathrm{E}-09$ & $1.02 \mathrm{E}-06$ & $1.02 \mathrm{E}-06$ \\
Electric arc furnace & $3.81 \mathrm{E}-08$ & $2.09 \mathrm{E}-08$ & $6.35 \mathrm{E}-06$ & $6.41 \mathrm{E}-06$ \\
Sinter plant & $1.89 \mathrm{E}-06$ & $1.40 \mathrm{E}-08$ & $3.34 \mathrm{E}-04$ & $3.36 \mathrm{E}-04$ \\
Coke-refining plant & $3.13 \mathrm{E}-10$ & $1.99 \mathrm{E}-11$ & $7.43 \mathrm{E}-08$ & $7.47 \mathrm{E}-08$ \\
Secondary aluminum & $1.53 \mathrm{E}-09$ & $1.16 \mathrm{E}-09$ & $3.07 \mathrm{E}-07$ & $3.10 \mathrm{E}-07$ \\
$\quad$ smelter & & & & \\
Cement kiln & $4.40 \mathrm{E}-16$ & $1.58 \mathrm{E}-12$ & $8.69 \mathrm{E}-14$ & $1.67 \mathrm{E}-12$ \\
Total risk & $1.93 \mathrm{E}-06$ & $3.76 \mathrm{E}-08$ & $3.42 \mathrm{E}-04$ & $3.43 \mathrm{E}-04$ \\
\hline
\end{tabular}




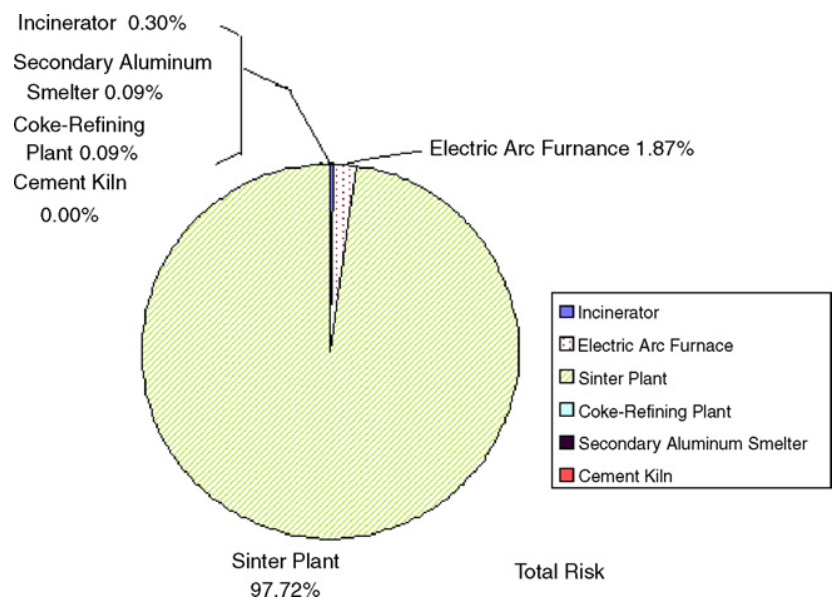

Fig. 2. . Risk contributions from the various types of emission sources in Siaogang District.

that stricter regulations on dioxin emission of electric arc furnaces and sinter plants were enacted in 2004 and 2005 in Taiwan, these large industrial emission sources still contribute most of the cancer risk of PCDD/Fs to the population living in the vicinity.

In contrast to sinter plants and electric arc furnaces, the other emission sources were much less than $1 \%$ of the total risk in the region. Among these emissions with low risk contributions, there is no regulation of dioxin emission concentration on the secondary aluminum smelter, cement plant and coke-refining plant at present, except for incinerators. While incinerators are probably regarded as the most important dioxin sources in the metropolis in recent years, it was found that the entire carcinogenic effect of five incinerators was only $0.3 \%$ of the total PCDD/Fs risk in the study. Fig. 2 shows pie charts of risk contributions categorized by source types under the site-specific exposure scenario.

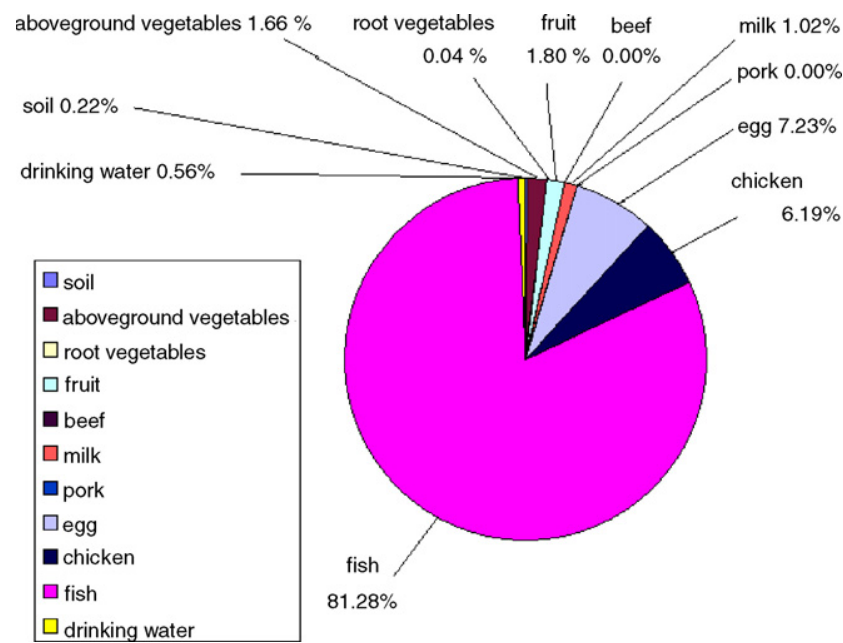

Fig. 3. Risk contributions from the 11 ingestion pathways in Siaogang District.

\subsubsection{Comparisons of exposure pathways}

Past studies of health risk assessment of PCDD/Fs suggested that food ingestion was the main exposure route of dioxin carcinogenic risk; however, the magnitude and distribution-ratio of total risks vary according to regional properties and the characteristics of emission sources. In general, people receive more than $90 \%$ of dioxin risk via daily food intake and less than $10 \%$ via inhalation. The results of the study showed that the cancer risk via ingestion is much higher than via inhalation, and exposure through food ingestion accounted for more than $99 \%$ of total dioxin risks in the Siaogang District.

Table 7 shows the risk distributions of the various exposure routes in site-specific exposure scenarios in the Siaogang District. The inhalation risk from a single emission source in the Siaogang District ranges from $3.39 \mathrm{E}-14$ to $1.72 \mathrm{E}-08$. Compared with the past studies, it was found that the dioxins concentrations in ambient air of the Siaogang District are

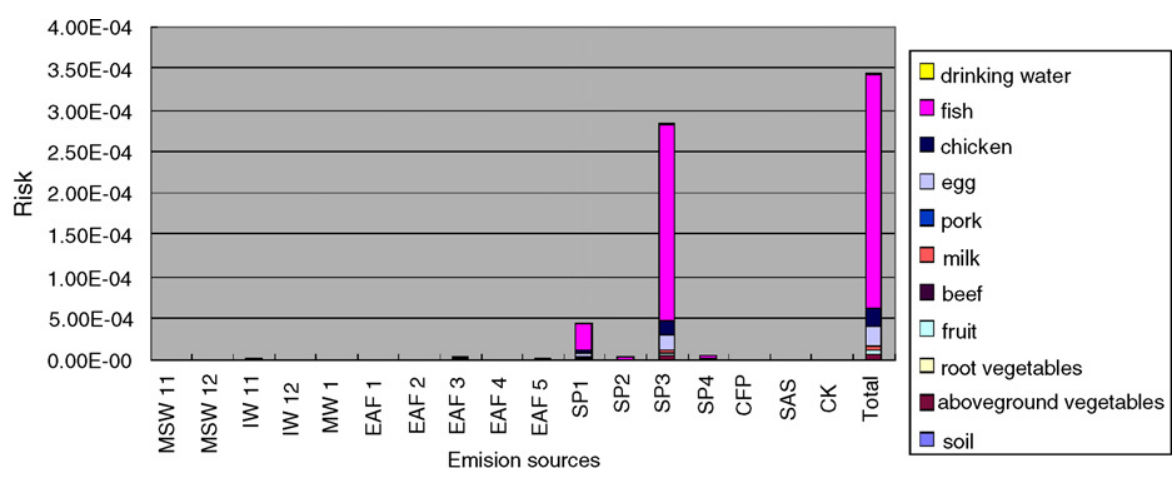

Fig. 4. Carcinogenic risk resulting from the 11 ingestion pathways of the 17 emission sources in Siaogang District.

Table 7

The risk distributions of exposure routes under site-specific exposure scenario

\begin{tabular}{lllll}
\hline Eexposure scenario & Ingestion & & Inhalation & \\
\cline { 2 - 5 } & Food items & Drinking water & Soil & $3.76 \mathrm{E}-08$ \\
\hline Risk values & $3.41 \mathrm{E}-04$ & $1.93 \mathrm{E}-06$ & $7.59 \mathrm{E}-07$ & $3.43 \mathrm{E}-04$ \\
\hline & 99.21 & 0.56 & 0.22 & 0.01 \\
\hline
\end{tabular}


higher than other places in Taiwan [25,26]. In accordance with the observations, this study found that the inhalation risks in the Siaogang District are higher than the other districts of Kaohsiung and the other cities in Taiwan. Inhalation risk is regarded as the most direct effect from emissions sources. There are many PCDD/Fs emission sources with large exit flows and emission rates in the impacted areas, so that the air concentration and wet and dry deposition of dioxin is higher. The incremental inhalation risk in the District is higher than $1 \mathrm{E}-08$ and is much greater than the total risks in other regions in Taiwan $[25,26]$.

In the study, we calculated the incremental contribution of PCDD/Fs risks from emission sources in the Siaogang District and assumed site-specific exposure scenarios, enabling us to obtain results for site-specific health risks represented as an effect of these stationary pollution sources. Thus, the assessment results should be lower than those when stricter assumptions on food ingestion are used. But it was found that the total risks were still higher than E-04, and the ingestion exposure was still the major route. The results presented above suggest that residents in the impact areas would experience a higher dioxin risk from inhalation and from ingestion. In fact, it should also be noted that these models predicted dioxin exposure from air deposition of emission sources, but not containing background contaminations of dioxins.

Fig. 3 is a pie chart showing the contributions of 11 ingestion pathways in the Siaogang District. Cancer risks from soil and drinking water accounted for less than $1 \%$. The results suggest that fish $(81.28 \%)$ is the main pathway of dioxin ingestion exposure in the Siaogang District. The pathways with less ingestion exposure were eggs (7.23\%), chicken $(6.19 \%)$, and fruit $(1.80 \%)$. The ingestion of fish was the most significant pathway, because the Siaogang District is a beachfront region with the largest port of Taiwan; the fishery is prevalent here and there are a large amount of aquatic products from the Siaogang District in the census. The Gaoping River contaminated by diffusion and wet deposition from the sources in this region was also assumed to produce edible fish product. To calculate the concentration in fish $\left(C_{\text {fish }}\right)$, the bioconcentration factor in fish $\left(\mathrm{BCF}_{\text {fish }}\right)$ was used as in the equation: $C_{\text {fish }}=C_{\mathrm{dw}} \times \mathrm{BCF}_{\text {fish }}$ to relate the concentration in fish $\left(C_{\text {fish }}\right)$ with the dissolved phase water concentration $\left(C_{\mathrm{dw}}\right)$.

The distribution of risks was correlated with the adult intake rates of the food groups in Taiwan and the agricultural production yields in Siaogang District through the site-specific exposure scenario. Fig. 4 shows bar charts of the risk distributions among 11 pathways of ingestion exposure of 17 emission sources. The results of the risk distributions in the nine food items are similar to another study about site-specific dioxin risk from emission sources in Taiwan [12].

\subsection{Uncertainty analysis}

The uncertainty in the risk assessment modeling process includes scenario uncertainty, model uncertainty, and parameter uncertainty and variability. In this section, parameter uncertainty analysis is presented; because the goal of the article is to understand the aggregate effect of various types of emission

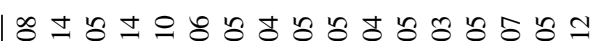

\author{
8
}

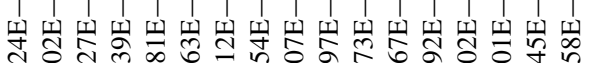

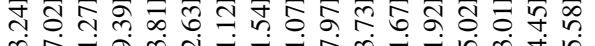

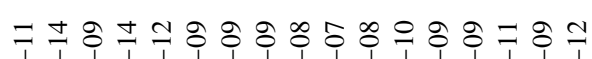

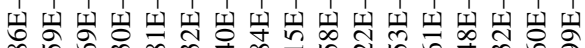

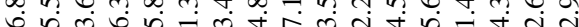

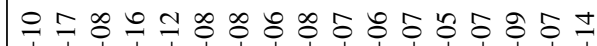

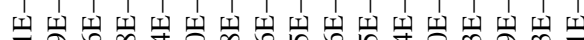
落

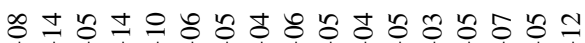

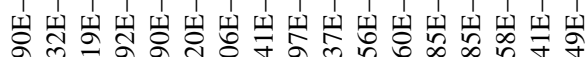

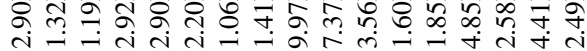

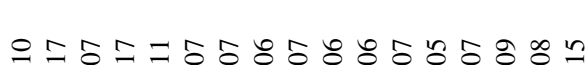

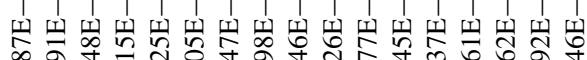
o- ma

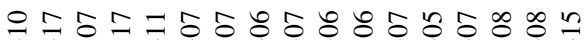

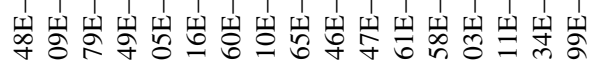


sources that are clustered in an industrialized region, and identify dominant dioxin sources in the region, detailed discussion of uncertainty analysis is not presented. There are three types of parameters in the multimedia risk assessment modeling: emission data, chemical properties, environmental properties, and exposure parameters. The multimedia risk assessment modeling comprised the air dispersion modeling, multimedia transport and transformation modeling and the multiple-pathway exposure modeling. The ISC-modeled concentrations and deposition rates of all congeners were used to derive probability distributions of air concentrations and deposition rates. In addition to the 17 congeners' air concentrations and deposition rates, there were 88 parameters related to properties of environmental media, 19 parameters related to exposure characteristics, and 427 parameters related to the 17 congeners' physicochemical properties.

In the study, the Monte Carlo method along with the multimedia risk assessment described above was used to combine individual probability distributions of model parameters to produce a probability distribution of risk estimation. Five thousand sets of simulations were conducted. Table 8 displays the risk values at the $95 \%$ cumulative probability distribution levels, categorized by environmental medium and exposure medium.

\section{Conclusion}

The study has combined the multimedia and multiple pathway exposure modeling and site-specific exposure scenario to perform dioxins risk assessment of emission sources clustered in an industrialized region. It was found that the major emission sources contributing to the risk of dioxins exposure were the sinter plants and electric arc furnaces, accounting for $99 \%$ of the aggregate health risk to residents in the area. The important exposure pathways were found to be ingestion of fish, eggs, and poultry. The assessments were made on the basis of the sitespecific exposure scenario to reflect the realistic intake status and agricultural yields in the study area.

The limitations of this research should be addressed in interpreting the study results. First, we determined the health risk of PCDD/Fs from emission sources only within the Siaogang District. However, the actual impact area of an emission source may be extended beyond the defined system boundary when it has a large amount of emissions, such as sinter plants and electric arc furnaces, or when it is located close to the region boundary, such as the cement kiln. Second, we have not assessed the background risks of dioxin and consider only the incremental health risks of stationary sources with PCDD/Fs emissions. Also, the change from the actual dioxin transfer by wholesale-market food is more complicated than this paper assumed because the ingestion risks of food groups from other places were not assessed in our study. We regarded agricultural products from places other than Siaogang District as non-polluted food. Third, average values were presented instead of addressing detailed uncertainty and variability distribution of the estimated risk, because the focus of this study was to examine the aggregate effects of numerous emissions concentrated in an area and provide directions for future management and research.
Despite these limitations, the results are still valid for making recommendations on future risk assessments and management of PCDD/Fs in the Siaogang District. Seeing that people in the Siaogang District whose daily dietary intake consists largely of locally produced food, we make an assertion that the actual risk received in the impacted areas may well be greater than the assessment results in this study. According to the results of these calculations, it is clear that residing in the Siaogang District could result in significant risks. The WHO has lowered its recommended tolerable daily intake (TDI) for dioxins to $1-4 \mathrm{pg}$ TEQ/kgBW-day. Most emission sources in the study could meet current regulations on dioxin emissions of stationary pollution sources from the analysis results of stack flue gas samples. However, these large-scale dioxin emission sources are all in or near the Siaogang District, so that the health risks of residents living in the region are high from both ingestion and inhalation. Thus, it is quite important to improve the monitoring and control of PCDD/Fs emission sources in the area in the future. The present practice may not be protective of the residents in the Siaogang District from the risks of dioxins. It suggested that the local authority should place high priority on implementing a management strategy of the aggregate risk encountered in this region. In line with enforcing a stricter local standard of dioxin emission in the District, a combination of replacing the Best Achievable Control Technology (BACT) with Maximum Achievable Control Technology (MACT) in air pollution prevention facilities, the total quantity control of PCDD/Fs emissions in the region, and in-house production process improvement could be considered in designing the management strategy in the region. The experience of this region should also be absorbed and applied to the issue of spatial arrangement of industrial facilities.

To improve the accuracy of dioxin-related health risk assessment in the future, it is suggested that the monitoring of emission sources and dioxin contents in environmental media and food items consumed by residents should be sustained over a longer period of time. A more detailed uncertainty analysis could also be conducted to understand the uncertainty and variability associated with the risk estimation. In sum, the results indicate that it is important to consider the aggregate risk in siting plants even though individual sources comply with regulatory standards.

\section{References}

[1] R.E. Alcock, R. Gemmill, K.C. Jones, Improvements to the UK PCDD/F and PCB atmospheric emission inventory following an emissions measurement programme, Chemosphere 38 (1999) 759-770.

[2] USEPA, Database of Sources of Environmental Release of Dioxin like Compounds in the United States, EPA/600/C-01/012, 2001.

[3] Japan Ministry of the Environment, Environmental Report on the Present Organic Pollutants (POPs) in Japan, 2002, pp. 40-55.

[4] U. Quass, M. Fermann, G. BröNoker, Identification of Relevant Industrial Sources of Dioxins and Furans in Europe (The European Dioxin Inventory). Final Report No. 43, Essen, Germany: Landesumweltamt Nordrhein-Westfalen, 1997.

[5] Umweltbundesamt, Determination of Requirements to Limit Emissions of Dioxins and Furans. Report from the Working Group of the Subcommittee Air/Technology of the Federal Government/Federal States Emission Control Committee, Berlin, Germany, 1996. 
[6] H. Fledler, Formation and sources of PCDD/PCDF, Organohalogen Compd. 11 (1993) 221-228.

[7] S. Caserini, A.M. Monguzzi, PCDD/Fs emissions inventory in the Lombardy Region: results and uncertainties, Chemosphere 48 (2002) 779-786.

[8] M. Schuhmacher, J.L. Domingo, J. Garreta, Pollutants emitted by a cement plant: health risks for the population living in the neighborhood, Environ. Res. 95 (2004) 198-206.

[9] L.C. Wang, W.J. Lee, P.J. Tsai, W.S. Lee, G.P. Chang-Chien, Emissions of polychlorinated dibenzo- $p$-dioxins and dibenzofurans from stack gases of sinter plants, Chemosphere 50 (2005) 1123-1129.

[10] C.M. Chen, The emission inventory of PCDD/PCDF in Taiwan, Chemosphere 54 (2004) 1413-1420.

[11] W.S. Lee, G.P. Chang-Chien, L.C. Wang, W.J. Lee, K.Y. Wu, P.J. Tsai, Emissions of polychlorinated dibenzo- $p$-dioxins and dibenzofurans from stack gases of electric arc furnaces and secondary aluminum smelters, J. Air Waste Manage. Assoc. 55 (2005) 1200-1207.

[12] H.W. Ma, Y.L. Lai, C.C. Chan, Transfer of dioxin risk between nine major municipal waste incinerators in Taiwan, Environ. Int. 28 (2002) 103-110.

[13] M. Meneses, M. Schuhmacher, J.L. Domingo, Health risk assessment of emissions of dioxins and furans from a municipal waste incinerator: comparison with other emission sources, Environ. Int. 30 (2004) 481-489.

[14] J.M. Llobet, J.L. Domingo, A. Bocio, C. Casas, A. Teixidó, L. Múller, Human exposure to dioxins through the diet in Catalonia, Spain: carcinogenic and non-carcinogenic risk, Chemosphere 50 (2003) 1193-1200.

[15] C.P. Dougherty, S.H. Holtz, J.C. Reinert, L. Panyacosit, D.A. Axelrad, T.J. Woodruff, Dietary exposure to food contaminants across the United States, Environ. Res. 84 (2000) 170-185.

[16] F.X. Rolaf van Leeuwen, M. Feeley, D. Schrenk, J. Christian, W. Farland, M. Younes, Dioxins: WHO's tolerable daily intake (TDI) revisited, Chemosphere 40 (2000) 1095-1101.
[17] USEPA, Human health and ecological risk assessment support to the development of technical standards for emissions from combustion units burning hazard wastes. Background document, EPA/68/w6/0053, 1999.

[18] NATO/CCMS, Scientific basic for the development of international toxicity equivalency factor (I-TEF) method of risk assessment for complex mixtures of dioxins and related compounds, Report 187, 1988.

[19] USEPA, Office of Research and Development, Cincinnati, Integrated Risk Information System (IRIS), 1992.

[20] R.M. Sedman, J.M. Polisini, J.R. Esparza, The evaluation of stack emissions from hazardous waste incinerators: assessing human exposure through non-inhalation pathways, Environ. Health Perspect. 102 (1994) $105-112$.

[21] Taiwan Department of Health, Nutrition and Health Survey in Taiwan, Taiwan, 1998 (in Chinese).

[22] Council of Agriculture, Food Supply and Utilization Yearbook 2003, Taiwan, 2004 (in Chinese).

[23] M. Schuhmacher, M. Meneses, A. Xifró, J.L. Domingo, The use of MonteCarlo simulation techniques for risk assessment: study of a municipal waste incinerator, Chemosphere 43 (2001) 787-799.

[24] H.W. Ma, Using stochastic risk assessment in setting information priorities for managing dioxin impact from a municipal waste incinerator, Chemosphere 48 (2002) 1035-1040.

[25] W.S. Lee, G.P. Chang-Chien, L.C. Wang, W.J. Lee, P.J. Tsai, K.Y. Wu, C. Lin, Sources Identification of PCDD/Fs for various atmospheric environments in a highly industrialized city, Environ. Sci Technol. 38 (2004) 4937-4944.

[26] Taiwan Department of Health, Dioxins in Taiwan Food and the Estimated Daily Intake in Taiwanese, Taiwan, 2002 (in Chinese). 